\title{
Effects of REM sleep deprivation on responding under multiple schedules of free-operant avoidance
}

\author{
CRAIG H. KENNEDY \\ Vanderbilt University, Nashville, Tennesee
}

\begin{abstract}
The effects of REM sleep deprivation on free-operant avoidance in rats was examined. Six rats were taught to press a lever to postpone shock for a fixed period of time after each response (responseshock [RS] interval). If they failed to press the lever, shocks were delivered after a fixed period of time (shock-shock [SS] interval). The subjects were exposed to a multiple schedule of reinforcement in which RS intervals were varied, but SS intervals were held constant. For each animal, baselines were established in which the length of the RS interval was inversely related to response rate. The subjects were then repeatedly exposed to 24,48 , or $96 \mathrm{~h}$ of REM sleep deprivation under identical tank control and cage control conditions. Compared with baseline and control conditions, REM sleep deprivation increased response rates. Increases in response rates were primarily accounted for by increases in brief interresponse times. The percentage of avoided shocks was not significantly altered across conditions.
\end{abstract}

Operant behavior occurs as a result of an interaction between environmental and biological events (Lubinski \& Thompson, 1986). Two primary determinants of operant behavior are positive and negative reinforcement (Catania, 1992). Positive reinforcement occurs when a persistent behavior reliably produces an event. Negative reinforcement occurs when a persistent behavior reliably removes an event or allows it to be avoided. Negative reinforcement typically involves avoidance or escape from noxious stimuli (Hineline, 1981). Examples of negative reinforcement in humans include one's asking a person not to shout when he is talking loudly, the removal of new shoes because they are uncomfortable, or a child's refusal to complete school work (Keller \& Schoenfeld, 1950/1995).

Biological events that alter behavior act primarily, although not exclusively, on an organism's central nervous system. Sleep deprivation is one such biological event. For example, the absence of sleep is associated with a wide variety of physiological effects, such as thermoregulatory dysfunction (Shaw, Bergmann, \& Rechtschaffen, 1998), alteration in the levels of neurotransmitters such as acetylcholine and serotonin (Jones, 1991), and disruption in synaptic plasticity related to memory consolidation (Smith, 1996). Along with physiological changes, sleep deprivation also alters behavior. For example, it has been shown to increase gross motor

This research was supported in part by funds from the University Research Council and the John F. Kennedy Center's Nicholas Hobbs Society at Vanderbilt University. The author thanks Mark Egli for his software support and Michael Kirby for his laboratory assistance. Correspondence should be addressed to C. H. Kennedy, John F. Kennedy Center, Box 40, Peabody College, Vanderbilt University, Nashville, TN 37203 (e-mail: craig.kennedy@vanderbilt.edu). activity in lab animals (Albert, Cicala, \& Siegel, 1970), as well as pain sensitivity (Ogilvie \& Broughton, 1976) and aggression (Hicks, Moore, Hayes, Phillips, \& Hawkins, 1979).

Recently, researchers have demonstrated that increased rates of negatively reinforced aggressive and/or selfdestructive behavior in humans is a function of sleep deprivation (R. H. Horner, Day, \& Day, 1997; Kennedy \& Itkonen, 1993; Kennedy \& Meyer, 1996; O’Reilly, 1995). Because of the potential importance of such findings for clinical diagnosis and treatment, the link between negatively reinforced responding and sleep deprivation has been studied using an animal model (Kennedy, Meyer, Werts, \& Cushing, 2000). In the Kennedy et al. (2000) study, rats were taught to leverpress in a free-operant avoidance task (i.e., behavior was negatively reinforced). After stable baselines of responding were achieved, the animals were REM sleep deprived for various durations. The Kennedy et al. (2000) results demonstrate that increases in avoidance responding is a function of REM sleep deprivation, relative to baseline or control conditions. Such findings indicate a previously undocumented effect of REM sleep deprivation on behavior that might also be of clinical interest.

The present experiment was designed to further explore the interrelation between REM sleep deprivation and various parameters of free-operant avoidance. The animals were placed on a multiple schedule of free-operant avoidance that varied the magnitude of reinforcement (via response-shock intervals) and response rates of individual animals in the avoidance sessions. The present study was designed to find out what effects various levels of REM sleep deprivation have on operants with differing response rates. 
Table I

Sequence of REM Sleep Deprivation (SD),

Tank Control (TC), and Cage Control Conditions (CC) for Each Animal and Hours of Exposure

\begin{tabular}{|c|c|c|c|c|c|}
\hline \multicolumn{6}{|c|}{ Subject } \\
\hline 2 & 15 & 18 & 21 & 22 & 25 \\
\hline $96 \mathrm{CC}$ & $96 \mathrm{CC}$ & 96SD & $24 \mathrm{CC}$ & $24 \mathrm{CC}$ & $96 \mathrm{SD}$ \\
\hline 48SD & 48SD & $24 \mathrm{TC}$ & $48 \mathrm{CC}$ & $48 \mathrm{CC}$ & $24 S$ \\
\hline 96SD & $24 \mathrm{CC}$ & $48 \mathrm{SD}$ & $24 \mathrm{SD}$ & $96 \mathrm{SD}$ & $48 \mathrm{~T}$ \\
\hline $24 \mathrm{TC}$ & $48 \mathrm{CC}$ & $24 \mathrm{CC}$ & 48SD & $24 \mathrm{SD}$ & $96 \mathrm{TC}$ \\
\hline 48SD & 48SD & $48 \mathrm{CC}$ & 24SD & $48 \mathrm{TC}$ & $24 \mathrm{Cl}$ \\
\hline $24 \mathrm{CC}$ & $24 S D$ & $24 S D$ & $48 \mathrm{TC}$ & $96 \mathrm{SD}$ & $24 \mathrm{TC}$ \\
\hline $48 \mathrm{CC}$ & $48 \mathrm{TC}$ & $48 \mathrm{SD}$ & $96 \mathrm{TC}$ & $48 \mathrm{SD}$ & $24 \mathrm{SL}$ \\
\hline 48SD & $96 \mathrm{TC}$ & $24 S D$ & 48SD & $24 \mathrm{TC}$ & $48 \mathrm{TC}$ \\
\hline 24SD & $48 S D$ & $48 \mathrm{TC}$ & $24 \mathrm{TC}$ & $96 \mathrm{CC}$ & $48 \mathrm{CC}$ \\
\hline $48 \mathrm{TC}$ & 24SD & 96SD & $48 \mathrm{TC}$ & $96 \mathrm{TC}$ & 96SD \\
\hline $96 \mathrm{TC}$ & 24SD & 48SD & $48 \mathrm{CC}$ & 48SD & $48 \mathrm{SL}$ \\
\hline $24 \mathrm{CC}$ & $96 \mathrm{SD}$ & $24 \mathrm{TC}$ & 96SD & 24SD & $96 \mathrm{CC}$ \\
\hline 24SD & $96 \mathrm{SD}$ & $96 \mathrm{CC}$ & 96SD & $96 \mathrm{CC}$ & $96 \mathrm{TC}$ \\
\hline $96 \mathrm{SD}$ & $24 S D$ & $96 \mathrm{TC}$ & $96 \mathrm{CC}$ & 48SD & 48SD \\
\hline $48 \mathrm{TC}$ & $48 \mathrm{CC}$ & $48 \mathrm{TC}$ & $24 \mathrm{CC}$ & $24 C C$ & $24 \mathrm{CC}$ \\
\hline $96 \mathrm{CC}$ & $24 \mathrm{CC}$ & $24 \mathrm{CC}$ & $96 \mathrm{CC}$ & $48 \mathrm{TC}$ & $24 \mathrm{SD}$ \\
\hline $96 \mathrm{TC}$ & $96 \mathrm{CC}$ & $96 \mathrm{CC}$ & 48SD & $24 S D$ & 96SD \\
\hline $48 \mathrm{CC}$ & $96 \mathrm{TC}$ & 48SD & 48SD & $24 \mathrm{TC}$ & $24 \mathrm{TC}$ \\
\hline 48SD & $24 \mathrm{TC}$ & $96 \mathrm{TC}$ & 24SD & 24SD & 24SD \\
\hline 24SD & $96 \mathrm{SD}$ & 96SD & 96SD & $48 \mathrm{SD}$ & 48SD \\
\hline $96 \mathrm{SD}$ & $24 \mathrm{TC}$ & $24 S D$ & $24 \mathrm{TC}$ & $96 \mathrm{TC}$ & 96SL \\
\hline $24 \mathrm{SD}$ & $48 \mathrm{TC}$ & $24 S D$ & 24SD & $96 \mathrm{SD}$ & $96 \mathrm{CC}$ \\
\hline $24 \mathrm{TC}$ & $96 \mathrm{SD}$ & 96SD & $96 \mathrm{SD}$ & 96SD & $48 \mathrm{CC}$ \\
\hline 96SD & 48SD & $96 \mathrm{CC}$ & $96 \mathrm{TC}$ & $48 \mathrm{CC}$ & $48 \mathrm{SD}$ \\
\hline
\end{tabular}

\section{METHOD}

\section{Subjects}

The subjects were 6 experimentally naive Sprague-Dawley male rats (numbered $2,15,18,21,22$, and 25 ). They were individually housed with $24 \mathrm{~h}$ ad-lib access to food and water; they weighed between 381 and $466 \mathrm{~g}$ at the start of the experiment and were kept on a 12:12-h light:dark cycle with lights on at 6:00 a.m. throughout the study.

\section{Apparatus}

BRS/LVE operant conditioning chambers, measuring $31 \mathrm{~cm}$ high, $31 \mathrm{~cm}$ long, and $26 \mathrm{~cm}$ wide, were used. Each chamber was placed in a sound attenuating container with a ventilation fan. Front and back walls were aluminum panels; the sides were made of clear Plexiglas. The instrument panel contained two levers, each placed $2.4 \mathrm{~cm}$ from the sides and $3.6 \mathrm{~cm}$ from the floor grid. A $28-\mathrm{V}$ houselight was placed at the top and center of the panel. Approximately $0.40 \mathrm{~N}$ of downward force actuated either lever. During sessions, $80 \mathrm{~dB}$ of white noise was presented via loudspeakers located in the experimental room. A sonalert that produced a $2900-\mathrm{Hz}$ tone at approximately $85 \mathrm{~dB}$ was mounted behind the instrument panel of each chamber. The floors consisted of 16 stainless steel rods spaced $1.5 \mathrm{~cm}$ apart. A constant-current shock generator and scrambler (MED Associates) was used to deliver a 1-mA shock for $0.5 \mathrm{sec}$ to the floor and instrument panel. The chambers were controlled by MED Associates hardware and by software run on an MMG 386 computer.

REM sleep deprivation was achieved by placing pairs of rats in specially constructed sleep deprivation tanks containing two platforms, each $7 \mathrm{~cm}$ in diameter, placed $15 \mathrm{~cm}$ apart. The tanks were cylindrical, approximately $1 \mathrm{~m}$ high and $0.7 \mathrm{~m}$ in diameter. Each rat was seated on a platform, which was raised $1 \mathrm{~cm}$ over a depth of $15 \mathrm{~cm}$ of water.

\section{Procedure}

Initial training. The animals were taught a free-operant avoidance response (Sidman, 1953). The shock-shock (SS) interval lasted $5 \mathrm{sec}$. The response-shock (RS) interval lasted $20 \mathrm{sec}$. The SS interval specified that shocks were to be delivered every $5 \mathrm{sec}$, unless either the right (for Rats 18 and 22) or the left (for Rats 2 , 15,21 , and 25) lever was actuated. Each time the lever was pressed, the RS interval was initiated and shock was postponed for $20 \mathrm{sec}$. A session began with the onset of houselight illumination, which was maintained for the daily $1 \mathrm{~h}$ session. Leverpressing was taught by placing the rat in a chamber for the duration of each session. Daily sessions continued until the animal avoided at least $75 \%$ of the programmed shocks per session for 10 consecutive sessions (this took between 10 and 19 sessions).

Multiple avoidance schedule. After initial training, the rats continued to be run in sessions at the same time of day, 7 days per week. However, a schedule of reinforcement different from that in training was used. The new schedule comprised a constant SS interval with alternating RS intervals (see Table 2). A session began with houselight illumination that accompanied the first component (the second component was accompanied by houselight illumination and tone). The first RS interval component was in place for $10 \mathrm{~min}$, followed by a 10-min blackout period (with no shock presented), and then by a 10 -min avoidance period with the second RS interval component and another 1-min blackout period. This sequence continued until an animal had been exposed to three repetitions of each RS interval per session. Data from the first two RS components of each session were not used in the data analysis (i.e., these were "warm-up" periods). Data from the other four components were used for data analysis throughout the study.

Once initial baseline stability was achieved (i.e., after 10 consecutive sessions of $\geq 75 \%$ avoidance was achieved and response rates appeared stable via visual inspection), the rats were exposed to the REM sleep deprivation, tank control, or cage control conditions (described below). After exposure to an experimental or control condition, each animal was placed in the operant chamber for an avoidance session. Beginning the next day, the animal resumed its daily avoidance regimen and continued until baseline stability was re-established (this took between 3 and 30 days). Each animal was then exposed to another experimental or control condition. This process continued until four exposures to each level of REM sleep deprivation and two exposures to each level of tank control and cage control conditions had occurred for each animal (see Table 1 for each animal's sequence of condition exposures).

REM sleep deprivation. The animals were exposed to 24,48 , or $96 \mathrm{~h}$ of REM sleep deprivation via the pedestal-over-water method. This technique eliminates approximately $\geq 98 \%$ of REM sleep, but does not affect slow-wave sleep (Maloney, Mainville, \& Jones, 1999). Each animal had ad-lib access to food and water while in the tanks.

Tank control. The animals were exposed to tank control conditions for 24,48 , or $96 \mathrm{~h}$. All aspects of the tank control condition were the same as those in the REM sleep deprivation condition, except that the animals were placed on two $16-\mathrm{cm}$ platforms. This condition controlled for possible behavioral effects that might be induced by exposure to the tank environments, but did not restrict sleep (Suchecki \& Tufik, 2000).

Cage control. Cage control conditions lasted for 24,48 , or $96 \mathrm{~h}$. In this condition, the animals were kept in their vivarium cage with ad-lib access to food and water. This condition controlled for possible behavioral effects that might be induced by the absence of avoidance sessions.

\section{Results}

Response rate. Response rates for each animal are arrayed in Table 2 . The table shows the number of responses per minute for each SS and RS interval combination per animal across baseline, REM sleep deprivation, tank control, and cage control conditions. The data for each experimental and control condition and those for each 
baseline session that was conducted prior to that condition are summarized in Table 2.

Subjects 2, 18, and 21 demonstrated increased rates of responding only in the $48 \mathrm{~h}$ REM sleep deprivation condition, but did not show significant changes in either of the control conditions. Subject 15 demonstrated elevated levels of responding in both the 48- and 96-h REM sleep deprivation conditions, but not in the control conditions. Subject 22 showed increased rates of responding across the 48- and 96-h REM sleep deprivation conditions on the 20 -sec RS interval, but not in the control conditions. However, this animal did show increased rates of responding in the 48- and 96-h REM sleep deprivation conditions and in the 96-h cage control condition on the 60-sec RS interval. Finally, Subject 25 showed significant but not systematic changes in response rate as a function of condition type and length of exposure. These differences were confirmed using within-subjects randomized-blocks analyses of variance (RBANOVAs) with post hoc Student's $t$ tests set at $p<.05$.

Figure 1 displays the response rate data from Table 2 as the percentage of change for each RS interval in REM sleep deprivation, tank control, and cage control conditions, relative to baseline. The data indicate that the increases in response rates that followed $48 \mathrm{~h}$ of REM sleep deprivation were greater for Rats 18,21 , and 22 in the longer RS interval component. Rats 2 and 15 did not show any differential elevations in response rates, and Rat 25 did not evidence any consistent pattern. This pattern of similarities and differences was confirmed using withinsubjects RBANOVAs with post hoc Student's $t$ tests set at $p<.05$.

Shock avoidance. Table 3 shows the number of shocks avoided per minute by animals across baseline, REM sleep deprivation, tank control, and cage control conditions for each RS interval. The number of shocks delivered was shown to be inversely related to RS interval length for each animal, with longer RS intervals associated with fewer shocks. The pattern for most of the animals indicated no significant difference in the number of shocks avoided across conditions or within RS intervals. Only Subject 25 demonstrated a statistically significant change in avoidance behavior across conditions. The change in avoidance behavior for Subject 25 tended to occur in the REM sleep deprivation and tank control conditions, but this was inconsistent. The data in Table 3 suggest that shock avoidance, except in the case of one animal, was not affected by REM sleep deprivation or control conditions, but was consistently affected by the length of the RS interval. These patterns were confirmed using within-subjects RBANOVAs with post hoc Student's $t$ tests set at $p<.05$.

Interresponse time. Given that response rates increased with no change in shock avoidance, a question remains about how REM sleep deprivation changed the pattern of responding that produced these results. Table 4 shows the number of $\leq 5$-sec interresponse times (IRTs) across conditions for each subject. The data were drawn from the same sessions in Table 3. As is indicated by the information in Table 4, REM sleep deprivation increased brief IRTs (i.e., $\leq 5 \mathrm{sec}$ ) for all animals except Subject 25 . Within-subjects RBANOVAs demonstrated this difference with post hoc Student's $t$ tests at $p<.05$.

\section{DISCUSSION}

REM sleep deprivation had several effects on the rats' response rates under multiple schedules of free-operant avoidance. The multiple schedules allowed for the establishment of two different response rates for each animal, permitting an analysis of the rate-dependent effects of REM sleep deprivation. All the animals demonstrated higher response rates and lower shock avoidance under the shorter RS interval schedule. The results demonstrated that $48 \mathrm{~h}$ of REM sleep deprivation consistently increased rates of avoidance responding. However, the increases in response rates were not associated with increases in the number of shocks avoided. Perhaps what is most intriguing about these findings is that REM sleep deprivation increased response rates, even though this was not adaptive for the animal in terms of avoiding shock.

Three animals $(18,21$, and 22$)$ demonstrated proportionally larger increases in response rates with longer RS intervals (and lower response rates) when they were REM sleep deprived for $48 \mathrm{~h}$. For example, response rates for Rat 18 increased by $77 \%$ under an RS 40 -sec schedule and by $57 \%$ under an RS 10 -sec schedule when REM sleep was deprived. However, two other animals ( 2 and 15 ) showed proportionally equivalent increases in response rates as a function of 48-h REM sleep deprivation. These data suggest that REM sleep deprivation increases avoidance response rates that have a tendency to produce proportionally larger rate increases for lower response rates (i.e., longer RS intervals).

In the present study, change in response rate was demonstrated to be a function of increased brief (i.e., $5 \mathrm{sec}$ or less) IRTs. Increases in brief IRTs were associated with increases in response rate, but not necessarily with increases in shock avoidance rates. This observation might explain why REM sleep deprivation increased response rates but did not affect shock avoidance rates.

Although not directly analyzed in the present study, it may be of future value to consider the neurobiological mechanisms responsible for the increased response rates. As was noted at the beginning, sleep is a complex neurological process that appears to serve a range of biological and psychological functions. However, researchers interested in understanding the neuropharmacology that underlies behavioral changes caused by REM sleep deprivation might want to consider that reductions in serotonin (5-HT) are a likely mechanism. First, as was also noted at the beginning, REM sleep deprivation has been associated with increases in pain sensitivity, motor ac- 


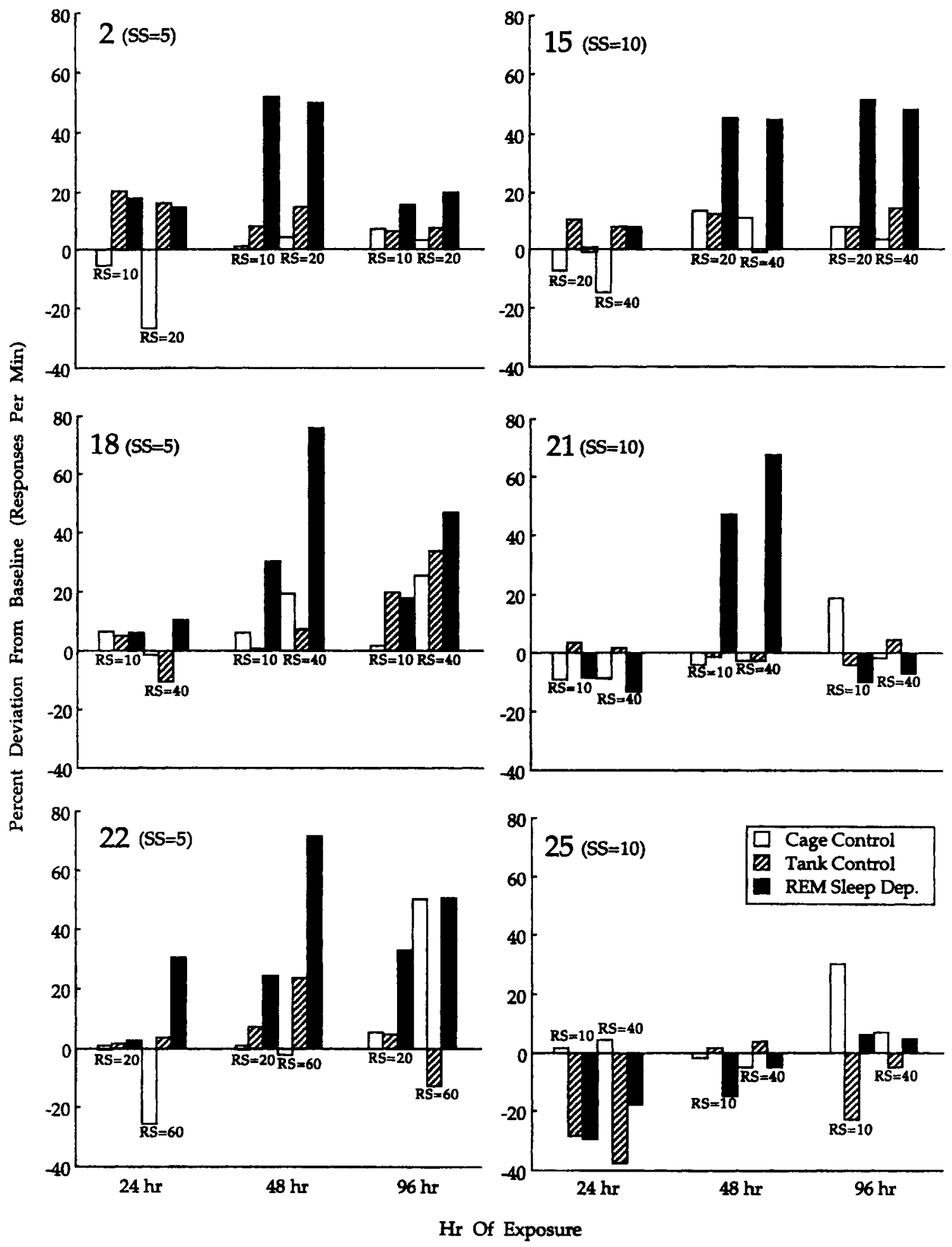

Figure 1. Changes in rate of responding from baseline to REM sleep deprivation, tank control, and cage control conditions for each rat. Data are expressed on the $y$-axis as percent deviation from baseline response rates. The $x$-axis arrays information by the number of hours of exposure and the response-shock (RS) interval (in seconds). 
Table 2

Mean Avoidance Responses per Minute (With Standard Errors) Across REM Sleep Deprivation (SD), Tank Control (TC), and Cage Control (CC) Conditions

\begin{tabular}{|c|c|c|c|c|c|c|c|c|c|c|c|c|c|c|c|c|c|c|c|c|}
\hline \multirow[b]{2}{*}{ Subjects } & \multicolumn{2}{|c|}{ Baseline } & \multicolumn{2}{|c|}{ 24-h CC } & \multicolumn{2}{|c|}{ 24-h TC } & \multicolumn{2}{|c|}{ 24-h SD } & \multicolumn{2}{|c|}{ 48-h CC } & \multicolumn{2}{|c|}{ 48-h TC } & \multicolumn{2}{|c|}{ 48-h SD } & \multicolumn{2}{|c|}{ 96-h CC } & \multicolumn{2}{|c|}{ 96-h TC } & \multirow{2}{*}{$\frac{96-\mathrm{h}}{M}$} & \multirow{2}{*}{$\frac{\mathrm{SD}}{S E}$} \\
\hline & $M$ & $S E$ & $M$ & $S E$ & $M$ & $S E$ & $M$ & $S E$ & $M$ & $S E$ & $M$ & $S E$ & $M$ & $S E$ & $M$ & $S E$ & $M$ & $S E$ & & \\
\hline \multicolumn{21}{|l|}{$2 \mathrm{SS}=5$} \\
\hline $\mathrm{RS}=10$ & 6.24 & 0.12 & 5.90 & 0.35 & 7.50 & 0.35 & 7.35 & 0.48 & 6.30 & 0.15 & 6.75 & 0.15 & 9.48 & 0.49 & 6.68 & 0.38 & 6.63 & 0.63 & 7.20 & 0.08 \\
\hline RS & 3.34 & 0.05 & 2.78 & 0.33 & 3.88 & 0.93 & 3.83 & 0.19 & 3.48 & 0.18 & 3.83 & 0.18 & 5.01 & 0.30 & 3.45 & 0 & 3.58 & 0.08 & 3.99 & 0.25 \\
\hline \multicolumn{21}{|l|}{$15 S S=10$} \\
\hline $\mathrm{RS}=20$ & 6.98 & 0.17 & 6.45 & 0.75 & 7.70 & 0.30 & 6.95 & 0.88 & 7.93 & 0.13 & 7.85 & 0.20 & 10.13 & 0.66 & 6.43 & 0.78 & 7.53 & 0.48 & 10.60 & 0.24 \\
\hline $\mathrm{RS}=40$ & 4.59 & 0.17 & 3.90 & 0.40 & 4.95 & 0.10 & 4.95 & 0.20 & 5.10 & 0.15 & 4.35 & 0.30 & 6.65 & 0.46 & 4.75 & 0.55 & 5.25 & 0.10 & 6.83 & 0.07 \\
\hline \multicolumn{21}{|l|}{$18 \mathrm{SS}=5$} \\
\hline 10 & 14.42 & 0.37 & 15.38 & 1.53 & 15.18 & 0.13 & 15.34 & .0 .29 & 15.33 & 0.58 & 14.53 & 0.23 & 18.76 & 0.42 & 16. & 0.93 & 17 & 0.83 & 16.98 & 1.12 \\
\hline $\mathrm{RS}=40$ & 8.15 & 0.24 & 8.03 & 0.68 & 7.28 & 2.03 & 9.00 & 0.57 & 9.73 & 0.18 & 8.75 & 1.15 & 14.33 & 0.74 & 10.20 & 0.85 & 10.90 & 1.35 & 11.94 & 0.78 \\
\hline \multicolumn{21}{|l|}{$21 \mathrm{SS}=10$} \\
\hline $\mathrm{RS}=10$ & 7.54 & 0.20 & 6.85 & 0.05 & 7.80 & 0.10 & 6.90 & 0.34 & 7.23 & 0.98 & 7.53 & 0.02 & 11.06 & 0.97 & 8.95 & 0.15 & 7.23 & 1.53 & 6.79 & 1.37 \\
\hline $\mathrm{RS}=40$ & 4.47 & 0.18 & 4.08 & 0.88 & 4.55 & 0.90 & 3.86 & 0.59 & 4.35 & 0.25 & 4.35 & 0.35 & 7.49 & 0.47 & 4.40 & 0.15 & 4.68 & 0.33 & 4.15 & 0.77 \\
\hline \multicolumn{21}{|l|}{$22 \mathrm{SS}=5$} \\
\hline & 4.38 & 0.06 & 4.38 & 0.43 & 4.45 & 0.10 & 4.50 & 0.19 & 4.38 & 0.78 & 4.70 & 0.80 & 5.45 & 0.13 & 4.63 & 0.43 & 4.60 & 0.20 & .83 & 0.78 \\
\hline $\mathrm{RS}=60$ & 2.89 & 0.11 & 2 & 0.35 & 3.00 & 0.20 & 3.78 & 0.73 & 2.83 & 0.38 & 3.58 & 0.53 & 96 & 0.45 & .35 & 0.55 & 53 & 0.23 & 4.36 & 0.57 \\
\hline \multicolumn{21}{|l|}{$25 \mathrm{SS}=10$} \\
\hline 10 & 5.76 & 0.16 & 5.85 & 0.28 & 4.13 & 1.03 & 4.08 & 0.91 & 5.65 & 1.27 & 5.85 & 0.40 & 4.91 & 0.81 & 7.50 & 0.85 & 4.43 & 0.63 & 6.13 & 0.60 \\
\hline $\mathrm{RS}=40$ & 2.92 & 0.11 & 3.05 & 0.30 & 1.83 & 0.58 & 2.40 & 0.29 & 2.78 & 0.08 & 3.03 & 0.48 & 2.78 & 0.47 & 3.13 & 0.18 & 2.78 & 0.58 & 3.06 & 0.44 \\
\hline
\end{tabular}

Note-SS, shock-shock interval; RS, response-shock interval; intervals measured in seconds.

tivity, and aggression; it is now associated with increased rates of avoidance responding.

Similar behavioral effects have been demonstrated in animals that have received $p$-chlorophenylalanine (PCPA) and 5-HT antagonist injections (Tanaka, Yoh, \& Takaori, 1972; Tennen, 1967). Interestingly, these effects have not been achieved when 5-hydroxytryptophan or 5-HT agonists have been administered (Aprison, Hingtgen, \& McBride, 1975; Park, Hingtgen, \& Aprison, 1991). In addition, the onset of REM sleep has been associated with decreases in 5-HT, particularly in the dorsal raphe nucleus (L. H. Horner, Sanford, Annis, Pack, \& Morrison, 1997; Portas et al., 1998; Portas \& Mcrarley, 1994). It is possible that reductions in 5-HT-due either to REM sleep deprivation or to administration of PCPA or 5-HT antagonists-cause behavioral changes similar to those caused by sleep deprivation because they share a common effect on serotonergic neurotransmission.

In addition to changes in 5-HT levels in the brain, acetylcholine (ACh) activity has also been found to be related to sleep states and their disruption. Jones (1991) noted that ACh activity increased as the sleep state moved

Table 3

Mean Number of Shocks per Minute (With Standard Errors) Across REM Sleep Deprivation (SD), Tank Control (TC), and Cage Control (CC) Conditions for Each Animal

\begin{tabular}{|c|c|c|c|c|c|c|c|c|c|c|c|c|c|c|c|c|c|c|c|c|}
\hline \multirow[b]{2}{*}{ Subjects } & \multicolumn{2}{|c|}{ Baseline } & \multicolumn{2}{|c|}{ 24-h CC } & \multicolumn{2}{|c|}{ 24-h TC } & \multicolumn{2}{|c|}{ 24-h SD } & \multicolumn{2}{|c|}{ 48-h CC } & \multicolumn{2}{|c|}{ 48-h TC } & \multicolumn{2}{|c|}{ 48-h SD } & \multicolumn{2}{|c|}{ 96-h CC } & \multicolumn{2}{|c|}{ 96-h TC } & \multicolumn{2}{|c|}{ 96-h SD } \\
\hline & $M$ & $S E$ & $M$ & $S E$ & $M$ & $S E$ & $M$ & $S E$ & $M$ & $S E$ & $M$ & $S E$ & $M$ & $S E$ & $M$ & $S E$ & $M$ & $S E$ & $M$ & $S E$ \\
\hline 255 & & & & & & & & & & & & & & & & & & & & \\
\hline & & 04 & 25 & 14 & 78 & 0.01 & 2.90 & .04 & 2.94 & 0.01 & 2.89 & .01 & 2.90 & 0.06 & 2.93 & .08 & 3.00 & 0.07 & & .04 \\
\hline & & & & & 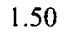 & & & 2 & 1.5 & 0 & 0 & 2 & & 2 & & 5 & & 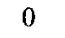 & & 0.0 \\
\hline$S$ & & & & & & & & & & & & & & & & & & & & \\
\hline & & & & 88 & & & & & & & & & & & & & & .46 & & 0. \\
\hline & & & 5 & 0.30 & & 0.02 & & 0.18 & 0.3 & 0.05 & & 6 & & & & 0.43 & & 0.07 & & 0.0 \\
\hline & & & & & & & & & & & & & & & & & & & & \\
\hline & & & & 0.06 & 8 & & 0.22 & $?$ & 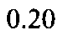 & 00 & 0. & 0 & & & & 1 & & 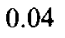 & & 0.0 \\
\hline & & & 0.02 & 0 & 0.04 & 0.0 & & 0.01 & 0.0 & 0.02 & 0.01 & 0.01 & & 0.04 & & 0.01 & & 0.01 & & 0.0 \\
\hline 8 & & & & & & & & & & & & & & & & & & & & \\
\hline & & & & 0 & & & & 9 & & & & 6 & & & & v & & 2 & & 0.6 \\
\hline & & & 0.76 & 0.36 & & & & 0.24 & & 0.05 & & 0.16 & & & & 0.08 & & 0.16 & & 0.3 \\
\hline$S$ & & & & & & & & & & & & & & & & & & & & \\
\hline & & & & & & & & o & & & & & & & & 0.14 & & 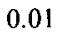 & & 0.2 \\
\hline & 5 & & 5 & 0.07 & 1 & 0.01 & & 0.05 & 0.19 & 0.14 & & 0.05 & & & & 0 & & 0.07 & & 0.0 \\
\hline & & & & & & & & & & & & & & & & & & & & \\
\hline & & & 3.2 & .62 & & & & 0.38 & 3. & 0.04 & & 0.48 & & & & 0.0 & & 0.62 & & 0.5 \\
\hline & 86 & 0.07 & 0.83 & .18 & 17 & 0.88 & 1.38 & 0.36 & 0.76 & 0.20 & 1.45 & 0.50 & 1.06 & 0.29 & 0.68 & 0.18 & 1.32 & 0.58 & 1.64 & 0.7 \\
\hline
\end{tabular}

Note-SS, shock-shock interval; RS, response-shock interval; intervals measured in seconds. 
Table 4

Percentage of Interresponse Times That Were $\leq 5$ Sec Across REM Sleep Deprivation (SD), Tank Control (TC), and Cage Control (CC) Conditions

\begin{tabular}{|c|c|c|c|c|c|c|c|c|c|c|}
\hline Rats & Baseline & 24-h CC & 24-h TC & 24-h SD & 48-h CC & 48-h TC & 48-h SD & 96-h CC & 96-h TC & 96-h SD \\
\hline $\begin{aligned} 2(\mathrm{SS} & =5) \\
\mathrm{RS} & =10 \\
\mathrm{RS} & =20\end{aligned}$ & $\begin{array}{l}57 \% \\
59 \%\end{array}$ & $\begin{array}{l}53 \% \\
62 \%\end{array}$ & $\begin{array}{l}64 \% \\
43 \%\end{array}$ & $\begin{array}{l}60 \% \\
55 \%\end{array}$ & $\begin{array}{l}59 \% \\
59 \%\end{array}$ & $\begin{array}{l}55 \% \\
61 \%\end{array}$ & $\begin{array}{l}79 \% \\
81 \%\end{array}$ & $\begin{array}{l}57 \% \\
60 \%\end{array}$ & $\begin{array}{l}51 \% \\
63 \%\end{array}$ & $\begin{array}{l}63 \% \\
58 \%\end{array}$ \\
\hline $\begin{array}{c}15(\mathrm{SS}=10) \\
\mathrm{RS}=20 \\
\mathrm{RS}=40\end{array}$ & & & & $\begin{array}{l}55 \% \\
53 \%\end{array}$ & $\begin{array}{l}63 \% \\
51 \%\end{array}$ & $\begin{array}{l}48 \% \\
47 \%\end{array}$ & & $\begin{array}{l}59 \% \\
51 \%\end{array}$ & $\begin{array}{l}57 \% \\
54 \%\end{array}$ & $\begin{array}{l}73 \% \\
71 \%\end{array}$ \\
\hline $\begin{array}{c}18(S S=5) \\
R S=10 \\
R S=40\end{array}$ & & & & $\begin{array}{l}69 \% \\
68 \%\end{array}$ & $\begin{array}{l}68 \% \\
75 \%\end{array}$ & $\begin{array}{l}71 \% \\
70 \%\end{array}$ & $\begin{array}{l}86 \% \\
84 \%\end{array}$ & $\begin{array}{l}77 \% \\
85 \%\end{array}$ & $\begin{array}{l}88 \% \\
82 \%\end{array}$ & $\begin{array}{l}80 \% \\
86 \%\end{array}$ \\
\hline $\begin{array}{c}21(\mathrm{SS}=10) \\
\mathrm{RS}=10 \\
\mathrm{RS}=40\end{array}$ & $65 \%$ & $63 \%$ & $63 \%$ & $63 \%$ & $67 \%$ & $\begin{array}{l}62 \% \\
66 \%\end{array}$ & $85 \%$ & $\begin{array}{l}74 \% \\
69 \%\end{array}$ & $\begin{array}{l}57 \% \\
61 \%\end{array}$ & $\begin{array}{l}61 \% \\
65 \%\end{array}$ \\
\hline $\begin{array}{c}2(S S=5) \\
R S=20 \\
R S=60\end{array}$ & $\begin{array}{l}59 \% \\
53 \%\end{array}$ & $\begin{array}{l}64 \% \\
51 \%\end{array}$ & $\begin{array}{l}58 \% \\
52 \%\end{array}$ & $\begin{array}{l}56 \% \\
56 \%\end{array}$ & $\begin{array}{l}62 \% \\
50 \%\end{array}$ & $\begin{array}{l}58 \% \\
49 \%\end{array}$ & $78 \%$ & $\begin{array}{l}59 \% \\
66 \%\end{array}$ & $\begin{array}{l}62 \% \\
57 \%\end{array}$ & $\begin{array}{l}79 \% \\
81 \%\end{array}$ \\
\hline $\begin{array}{c}25(\mathrm{SS}=10) \\
\mathrm{RS}=10 \\
\mathrm{RS}=40\end{array}$ & $\begin{array}{l}45 \% \\
51 \% \\
\end{array}$ & $52 \%$ & $49 \%$ & $51 \%$ & $55 \%$ & $52 \%$ & $56 \%$ & $49 \%$ & $\begin{array}{l}45 \% \\
51 \% \\
\end{array}$ & $\begin{array}{l}49 \% \\
53 \% \\
\end{array}$ \\
\hline
\end{tabular}

Note-SS, shock-shock interval; RS, response-shock interval; intervals are measured in seconds.

closer to REM sleep and then peaked during this stage. Similarly, Mallick and Thakkar (1992) demonstrated that cholinergic levels, as measured by acetylcholinesterase activity, remained high in rats after deprivation of REM sleep. These findings, along with behavioral evidence for an increase in avoidance responding resulting from exposure to ACh agonists (Balfour, 1990; Hamilton \& Grossman, 1969; Ross \& Grossman, 1974), suggest a possible role for cholinergic mechanisms involved in the effects of REM sleep deprivation on behavior. However, the viability of the proposed 5-HT and ACh mechanisms and their possible interactions, await further behavioral, neuropharmacological investigation.

Finally, from a clinical perspective, sleep deprivation has been associated with increased aggression and selfinjury in people with developmental disabilities (R. H. Horner et al., 1997; Kennedy \& Itkonen, 1993; Kennedy \& Meyer, 1996; O'Reilly, 1995). In particular, aggression and self-injury function as ways to avoid or escape noxious stimuli-that is, they are negatively reinforced behaviors-and are particularly sensitive to the effects of sleep deprivation. The results of the present study parallel previous clinical findings and provide additional evidence for the role of sleep deprivation in increasing problem behavior. The fact that people with developmental disabilities, including autism and Rett syndrome, experience sleep disorders at a rate much higher than other populations (Brylewski \& Wiggs, 1998; Piazza, Fisher, \& Kahng, 1996; Quine, 1991) suggests that increased attention should be paid by physicians and psychologists to the comorbidity of sleep problems and problem behavior in this particular population. Whether the previously noted changes in serotonergic and/or cholinergic neurotransmission observed in laboratory settings are func- tionally involved in human behavioral changes associated with sleep deprivation awaits future analysis.

\section{REFERENCES}

Albert, I.. Cicala, G. A, \& Siegel, J. (1970). The behavioral effects of REM sleep deprivation in rats. Psychophysiology, 6, 550-560.

Aprison, M. H., Hingtgen, J. N., \& McBride, W. J. (1975). Serotonergic and cholinergic mechanisms during disruption of approach and avoidance behavior. Federation Proceedings, 34, 1813-1822.

BALFOUR, D. J. (1990). A comparison of the effects of nicotine and (+)amphetamine on rat behaviour in an unsignalled Sidman avoidance schedule. Journal of Pharmacy \& Pharmacology, 42, 257-260.

BRYLEWSKI. J. E., \& WIGGS, L. (1998). A questionnaire survey of sleep and night-time behaviour in a community-based sample of adults with intellectual disability. Journal of Intellectual Disability Research, 42, 154-162.

Catania. A. C. (1992), Learning (3rd ed.). Englewood Cliffs, NJ: Prentice-Hall.

Hamilton, L. W., \& Grossman, S. P. (1969). Behavioral changes following disruption of central cholinergic pathways. Journal of Comparative \& Physiological Psvchology, 69, 76-82.

Hicks, R. A., Moore, J. D., Hayes, C., Phillips, N., \& Hawkins, J. (1979). REM sleep deprivation increases aggressiveness in male rats. Physiology \& Behavior, 22, 1097-1100.

HiNeline, P. N. (1981). The several roles of stimuli in negative reinforcement. In P. Harzem \& M. D. Zeiler (Eds.), Predictability, correlation, and contiguity (pp. 123-146). New York: Wiley.

Horner, L. H., SANFord, L. D., Annis, D., Pack, A. I., \& Morrison, A. R. (1997). Serotonin at the laterodorsal tegmental nucleus suppresses rapid-eye-movement sleep in freely behaving rats. Journal of Neuroscience, 17, 7541-7552.

HORNER, R. H., DAY, H. M., \& DAY, J. R. (1997). Using neutralizing routines to reduce problem behaviors. Journal of Applied Behavior Analvsis, 30, 601-614.

JONES, B. E. (1991). Paradoxical sleep and its chemical/structural substrates in the brain. Neuroscience, 40, 637-656.

Keller, F. S., \& SChoenfeld. N. (1995). Principles of psychology. Cambridge. MA: B. F. Skinner Foundation. (Original work published 1950)

KenNEDY, C. H., \& ITKONEN, T. (1993). Effects of setting events on the 
problem behavior of students with severe disabilities. Journal of $A p$ plied Behavior Analysis, 26, 321-327.

Kennedy, C. H., \& Meyer, K. A. (1996). Sleep deprivation, allergy symptoms, and negatively reinforced problem behavior. Journal of Applied Behavior Analysis, 29, 133-135.

Kennedy, C. H., Meyer, K. A., Werts, M. G., \& Cushing L. S. (2000). Effects of sleep deprivation on free-operant avoidance. Journal of the Experimental Analysis of Behavior, 74, 333-345.

LUBiNsKi, D., \& Thompson, T. (1986). Functional units of human behavior and their integration: A dispositional analysis. In T. Thompson \& M. D. Zeiler (Eds.), Analysis and integration of behavioral units (pp. 275-314). Hillsdale, NJ: Erlbaum.

Mallick, B. N., \& ThakKar, M. (1992). Effects of REM sleep deprivation on molecular forms of acetylcholinesterase in rats. NeuroReport, 3, 676-678.

Maloney, K. J., Mainville, L., \& Jones, B. E. (1999). Differential cFos expression in cholinergic, monoaminergic, and GABAergic cell groups of the pontomesencephalic tegmentum after paradoxical sleep deprivation and recovery. Journal of Neuroscience, 19, 30573072.

Ogilvie, R. D., \& Broughton, R. J. (1976). Sleep deprivation and measures of emotionality in rats. Psychophysiology, 13, 249-260.

O'ReiLlY, M. F. (1995). Functional analysis and treatment of escapemaintained aggression correlated with sleep deprivation. Journal of Applied Behavior Analysis, 28, 225-226.

Park,W. K., Hingtgen, J. N., \& Aprison, M. H. (1991). Differential effect of 5-hydroxytryptophan on approach and avoidance behavior in rats. Pharmacology, Biochemistry \& Behavior, 38, 191-194.

Piazza, C. C., Fisher, W. W., \& KaHng, S. W. (1996). Sleep patterns in children and young adults with mental retardation and severe behavior disorders. Developmental Medicine \& Child Neurology, 38, 335-344

Portas, C. M., Bjorvatn, B., Fagerland, S., Grønli, J., Mundal, V., Sørensen, E., \& URSin, R. (1998). On-line detection of extracellu- lar levels of serotonin in dorsal raphe nucleus and frontal cortex over the sleep/wake cycle in freely moving rat. Neuroscience, 83, 807-814.

PORTAS, C. M., \& MCCARley, R. W. (1994). Behavioral state-related changes of extracellular serotonin concentration in the dorsal raphe nucleus: A microdialysis study in the freely moving cat. Brain Research, 648, 306-312.

QUINE, L. (1991). Sleep problems in children with mental handicap. Journal of Intellectual Disability Research, 35, 269-290.

Ross, J. F., \& Grossman, S. P. (1974). Intrahippocampal application of cholinergic agents and blockers: Effects on rats in differential reinforcement and Sidman avoidance paradigms. Journal of Comparative \& Physiological Psychology, 86, 590-600.

Shaw, P. J., BergmanN, B. M., \& Rechtschaffen, A. (1998). Effects of paradoxical sleep deprivation on thermoregulation in the rat. Sleep, 21, 7-17.

Sidman, M. (1953). Avoidance conditioning with brief shock and no exteroceptive warning signal. Science, 118, 57-58.

Sмiтh, C. (1996). Sleep states, memory processes and synaptic plasticity. Behavior \& Brain Research, 78, 49-56.

Suchecki, D., \& TUFIK, S. (2000). Social stability attenuates stress in the multiple platform method for paradoxical sleep deprivation in the rat. Physiology \& Behavior, 68, 309-316.

TANAKa, C., YoH, Y., \& TAKaORI, S. (1972). Relationship between brain monoamine levels and Sidman avoidance behavior in rats treated with tyrosine and tryptophan hydroxylase inhibitors. Brain Research. 45, 153-164.

TENNEN, S. S. (1967). The effects of $p$-chlorophenylalanine, a serotonin depletor, on avoidance acquisition, pain sensitivity and related behavior in the rat. Psychopharmacologia, 10, 204-219.

(Manuscript received April 19, 2000: revision accepted for publication July 7,2000 .) 